\title{
Implantation of an ICD Lead to an Unusual Site
}

\author{
Ahmet Korkmaz ${ }^{1}$, Ozcan Ozeke ${ }^{2}$, Meryem Kara ${ }^{2}$, Firat Ozcan ${ }^{2}$, Serkan Cay $^{3}$, Serkan \\ Topaloglu' ${ }^{2}$, and Dursun $\mathrm{Aras}^{2}$ \\ ${ }^{1}$ 1. Ankara City Hospital Department of Cardiac Electrophysiology Üniversiteler Mahallesi \\ Bilkent Cad. No:1 Çankaya Ankara/Turkey 06800 \\ ${ }^{2}$ University of Health Sciences, Ankara City Hospital, Department of Cardiology, Division \\ of Arrhythmia and Electrophysiology, Ankara, 06800, TR \\ ${ }^{3}$ University of Health Sciences, Ankara City Hospital
}

April 28, 2020

\begin{abstract}
Implantable cardioverter-defibrillators (ICDs) are routinely used for primary and secondary prevention of arrhythmia-related deaths in patients with heart failure and reduced left ventricular ejection fraction.Various early and late complications have been well described in the literature during transvenous ICD implantation. This case report describes an unusual site ICD lead implantation.
\end{abstract}

\section{Title page}

Case report

\section{İmplantation of an ICD Lead to an Unusual Site}

Ahmet Korkmaz ${ }^{1}$

Özcan Özeke ${ }^{2}$

Meryem Kara ${ }^{1}$

Firat Özcan ${ }^{2}$

Serkan Cay $^{2}$

Serkan Topaloglu ${ }^{2}$

Dursun $\operatorname{Aras}^{2}$

1. Ankara City Hospital, Department of Cardiology, Ankara, Turkey.

2. University of Health Sciences, Ankara City Hospital, Department of Cardiology, Division of Arrhythmia and Electrophysiology, Ankara, Turkey.

Corresponding author:

Ahmet Korkmaz, drahmtkrkmz07@gmail.com

Ankara City Hospital, Department of Cardiology, Ankara, Turkey.

İmplantation of an ICD Lead to an Unusual Site

Introduction 
Implantable cardioverter-defibrillators (ICDs) are routinely used for primary and secondary prevention of arrhythmia-related deaths in patients with heart failure and reduced left ventricular ejection fraction(1-2) Various early and late complications have been well described in the literature during transvenous ICD implantation( 3-4). This case report describes an unusual site (coronary sinüs) ICD lead implantation.

\section{Case report}

A 70-years-old man with a ischemic cardiomyopathy underwent ICD implant at an outside institution for primary prevention of sudden cardiac death three years ago. The ICD was a Medtronic Maximo II VR with a dual-coil VVI ICD lead. Two weeks ago the patient experienced a shock. The electrocardiography showed NSR (Figure 1). Device interrogation demonstrated that the stored intracardiac electrograms (EGMs) of the events are shown in Figures 2-3. The analysis of the episode revealed a sudden change to very rapid and irregular myocardial activity with EGM alternans that reach VF zone and a shock is delivered that restores sinus rhythm (Figure 3 ). Chest X-ray and fluoroscopy showed the active ICD lead was in the coronary sinus (Figure 4). There was no ventricular capture with pacing from ICD (Figure 5). This could only be explained by sensing of atrial signal during an acute AF in the ICD lead, probably due to inappropriate lead implantation to the coronary sinus during the first procedure. The patient has been treated with new single coil active ICD lead implantation to the right ventricule and old ICD electrode left in place (Figure 6).

\section{Discussion}

The most common causes of inappropriate ICD therapies are supraventricular tachycardia, especially AF or atrial flutter with rapid ventricular response, T-wave oversensing, and lead dysfunction (noise and myopotentials)(5). Dislodgement and migration of cardiac implantable electronic device leads are not uncommon, however leads placement in inappropriate areas is extremely rare.

The coronary sinus (CS) has become a clinically important structure especially through its role in providing access for different cardiac procedures(6). Accurate knowledge of the coronary venous anatomy is essential for electrophysiologists performing left ventricular pacing procedures or radiofrequency ablation. In our case ICD lead implantation into the coronary sinus with AF led to inappropriate unsynchronized shock that returned AF to normal sinus rhythm. Probably, due to the normal $\mathrm{R}$ wave sensitivity and the tests of pacing threshold being performed without ECG in device controls, it was not noticed that the lead was not at the proper location. Another reason may be that chest x-rays are not interpreted correctly.

In some cases, implantation of the lead into the coronary sinus can be needed.Various conditions requiring implantation into the coronary sinus are as follows; anatomical barriers that preclude the passage through the valve such as atresia, stenosis and mechanical prosthesis, failed implantation into the ventricle, presence of persistent left superior vena cava with absence of right sided vein making the implantation near impossible, presence of abnormal ventricular substrate resulting in abnormal elevation of the capture threshold, and high defibrillation threshold(7-10).

\section{Conclusion}

Perioperative and postoperative ICD care is important to prevent any untoward harm to patients. Routine postoperative interrogation of the ICD should be done by the cardiac electrophysiologist and following the simple and basic rules sometimes ECG and chest X-ray can demonstrate lead misplacement or displacement.

\section{References}

1. Yancy C.W, Jessup M, Bozkurt B. 2017 ACC/AHA/HFSA Focused Update of the 2013 ACCF/AHA Guideline for the Management of Heart Failure: A Report of the American College of Cardiology/American Heart Association Task Force on Clinical Practice Guidelines and the Heart Failure Society of America. J Card Fail. 2017;23:628-651.

2. Kusumoto FM, Bailey KR, Chaouki AS, Deshmukh AJ, Gautam S, Kim RJ,et al. Systematic review for the $2017 \mathrm{AHA} / \mathrm{ACC} / \mathrm{HRS}$ guideline for management of patients with ventricular arrhythmias and the prevention of sudden cardiac death: A Report of the American College of Cardiology/American Heart 
Association Task Force on Clinical Practice Guidelines and the Heart Rhythm Society. Heart Rhythm. 2018 Oct;15(10):e253-e274.

3. Van Rees J.B, De Bie M.K, Thijssen J, Borleffs C.J, Schalij M.J, Van Erven L. Implantation-related complications of implantable cardioverter-defibrillators and cardiac resynchronization therapy devices: a systematic review of randomized clinical trials. J Am Coll Cardiol. 2011;58:995-1000.

4. Yaminisharif A, Soofizadeh N, Shafiee A, Kazemisaeid A, Jalali A, Vasheghani-Farahani A. Generator and lead-related complications of implantable cardioverter defibrillators. Int Cardiovasc Res J. 2014 Apr;8(2):6670.

5. Shah H, Mezu U, Patel D, Flanigan S, Hreybe H, Adelstein E, et al. 2013. Mechanisms of inappropriate defibrillator therapy in a modern cohort of remotely monitored patients. Pacing Clin. Electrophysiol. $36: 547-552$.

6. Gerber TC, Kantor B, Keelan PC, Hayes DL, Schwartz RS, Holmes DR. The coronary venous System: an alternate portal to the myocardium for diagnostic and therapeutic procedures in invasive cardiology. Curr Interv Cardiol Rep 2000;2:27-37

7. Rodriguez-Manero M, Kreidieh B, Ibarra-Cortez SH, Alvarez P, Schurmann P, Dave AS, et al. Coronary vein defibrillator coil placement in patients with high defibrillation thresholds. J Arrhythm. 2018 Dec $3 ; 35(1): 79-85$.

8. Cay S, Ozeke O, Kara M, Ozcan F, Aras D, Topaloglu S. Migration of a Pacemaker Lead to an Unusual Site. Acta Cardiol Sin. 2018 Nov;34(6):539-540.

9. Bilchick KC, Judge DP, Calkins H, Marine JE. Use of a coronary sinus lead and biventricular ICD to correct a sensing abnormality in a patient with arrhythmogenic right ventricular dysplasia/cardiomyopathy. J Cardiovasc Electrophysiol. 2006 Mar;17(3):317-20.

10.Cay S. Transvenous cardioverter-defibrillator lead implantation in a patient with three mechanical prosthetic valves: all in one solution. Int J Cardiol 2013;165:e33-4.

\section{Hosted file}

$\backslash$ selectlanguage\{polish\} \\selectlanguage\{english\}cd ks g\selectlanguage\{ngerman\}örüntüler.docx available at https://authorea.com/users/313239/articles/443800-i\%CC\%87mplantation-of -an-icd-

lead-to-an-unusual-site 